\title{
Logistic risk assessment in distribution infrastructure of medicines produced in the Ural Federal District
}

\author{
Alexey Petrov, Anna Kantorovich*, and Galina Andrianova \\ Ural State Medical University, Department of management and economics of pharmacy, 620109, 3, \\ Repina st., Ekaterinburg, Russia
}

\begin{abstract}
The article describes the results of structural-functional analysis of medicines distribution system in the Ural Federal District (Ural FD). The structure of material flow is heterogeneous in the indicator of logistics channels diversification: the share of trade turnover at federal distributors varies from 17.2 to $100 \%$. There was also an increase in the share of the federal distribution with an increase in the cost of the medication. Methodical approach to risk assessment of pharmaceutical distribution logistics in the Ural FD on the basis of commercial and logistic risk multiplier has been developed and tested. Mathematical modeling of the federal suppliers' demand for medicines produced in the Urals and the supply of Ural manufacturers with medicines was carried out. Based on the obtained results, methods of reducing the risks of distribution logistics are proposed; in particular, diversification of distribution channels in the range of selling prices of producers excl.VAT from 600 to 800 rubles per package, including by attracting Ural state unitary enterprises with a license for wholesale pharmaceutical activity. In addition, active promotion of expensive medications (more than 700 rubles) is recommended to reduce risks in their distribution and demand increase of federal distributors that will reduce the cost of medications and create additional availability for geriatric use.
\end{abstract}

\section{Introduction}

At the present stage of pharmaceutical logistics development in the Russian Federation, new trends have been identified. First of all, this sector of the pharmaceutical market is characterized by integration processes involving logistics agents with a high delegation degree of logistics procedures and innovative digital logistic platforms; in addition, consolidation of trade turnover in large federal suppliers is preserved [1]. The industry development vector to attract innovative intermediary agents has obviously much to do with the desire of large and medium-sized players to administer their logistical risks [2-6]. In this regard, it is particularly interesting to assess the Ural FD pharmaceutical industry entity inclusion in the structural transformation of the logistics services market. As an industry, pharmaceutical logistics is characterized by high commercial, organizational and financial

\footnotetext{
* Corresponding author: kant.anna@icloud.com
} 
risks; with this, micrologistic systems of the medications manufacturing enterprises in the Ural FD form additional economic, marketing and reputational risks while being included in the national macrologistic system of pharmaceutical products distribution $[7,8]$. It should be noted that the marketing logistics risks in pharmaceutical distribution channels reduce the availability of medicinal care primarily for socially vulnerable categories of citizens - in particular, for patients of older age groups in geriatric practice [9]. The studies aimed at the development of valid logistic risks assessment methods of medicines manufacturing enterprises localized in the Ural FD are actual within the framework of the medications distribution channels.

Therefore, the purpose of the study was to develop and test a methodical approach to risk assessment of the Ural FD pharmaceutical industry subjects in the pharmaceutical market distribution logistics system with the justification of a targeted measures set to optimize the marketing logistics of enterprises in order to increase the availability of medicinal aid to the population and added competitiveness formation of medicinal products produced in the Urals.

\section{Materials and Methods}

The object of the study was pharmaceutical plants localized in the Ural FD (medications manufacturing enterprises having a license to manufacture medicines on the register of licenses of the Ministry of Industry and Trade of the Russian Federation as of January 1, 2020). Sampling exclusion factors: license absence, absence of registered vital and essential medications in the portfolio as of January 1, 2020. 9 enterprises were included in the sample: "Sintez" OJSC, "Irbit Khimpharmzavod" OJSC, "Velpharm" LLC, “Zavod Medsintez" LLC, "Pharmasyntez-Tyumen" LLC, "Uralbiopharm" OJSC, "Berezovsky Pharmaceutical Plant" CJSC ("Lekas"), "Tyumen Khimpharmazavod" OJSC, "Lumi" LLC. The content analysis results of specialized pharmaceutical information systems "Svodny zakaz", "Eprika" were used; quadruple panel detection of the magnitude inventory and price characteristics of wholesale stock remainders at the beginning of the I, II, III, IV quarters of 2019 (stock control on 474 medicines' trade names) was carried out. Results of content analysis of official financial statements of pharmaceutical enterprises were used in the studied sample. The methodical approach basis was formed by the results of situational analysis of the medicines distribution system produced in the Ural FD; the structural-functional analysis results of pharmaceutical logistic system of the Ural FD; economic analysis results on pricing in pharmaceutical market wholesale segment; results on organizational and pharmaceutical proposals analysis in the pharmaceutical industry segment of the Ural FD with elements of financial analysis; mathematical modeling results on supply and demand in pharmaceutical market wholesale segment of the Ural FD; results on organizational and pharmaceutical risks analysis of pharmaceutical logistics. Software products MS Excel, Statistics 12.0 were used to process the results and construct infographics.

\section{Results and Discussion}

To achieve the goal of scientific research, we proposed an algorithm for systemic risk analysis in the distribution logistics of medicines produced in the Ural FD. The methodical approach consists of three key stages: structural-functional analysis of medications distribution system, organizational and pharmaceutical metrics substantiation on logistic risks of medicines manufacturers in the Ural FD, modeling of emerging risks in the context of individual pharmaceutical plants of the Ural FD. The simulation results were used to form 
targeted optimization recommendations for the pharmaceutical industry subjects of the Ural FD.

At the first stage, the structural and functional analysis of medicines distribution system in the Ural FD was carried out. The peculiarity of the pharmaceutical market is distribution logistics with the participation of a specific wholesale agent — the medicines wholesale trade enterprise; distribution channels are mainly indirect with a steady trade concentration in a limited number of federal distributors.

In order to structurize the distribution system of medicines produced in the Ural FD, wholesale enterprises represented in the district regions were divided into three levels in terms of market coverage. Companies engaged in wholesale PL trade in more than three subjects of Russia ("NPK "Katren" JSC, Firma SV "Protek" CJSC, "FK Puls" LLC) were classified as federal level suppliers. Suppliers represented in 2-3 subjects were classified as interregional ("Agroresursy" LLC, "Regionalny Aptechny Sklad" JSC, "BSS" LLC, "Godovalov" LLC); companies operating in one subject of the Russian Federation were accepted as regional suppliers ("MO "Novaya Bolnitsa" LLC, "Uralbiopharm" JSC, "Pharmacia" SUE SO).

In order to assess the material flow structure, the software platforms of wholesale pharmaceutical supply aggregators "Svodny zakaz", "Eprica" were used. Observations were conducted during 20194 times at the beginning of each quarter. The object of observation was wholesale stock remainders in the enterprises of wholesale medicines trade under 474 trade names (TN) of medicines produced in the Ural FD. At the same time, panel quadruple detection of each TN packages number during 2019 was conducted; according to the observation results, the average annual inventory for different levels of each item was calculated. To increase visibility, the values of the average annual MP stock were given a rank estimation parameter ranging from 1 to 3 . Thus, medical preparation with an average annual stock of 1 to 300 packages was given an estimated parameter of 1 , for items with an average annual inventory of 301-600 packages - parameter 2, parameter 3 was given to items with an average annual inventory of more than 600 packages. As a result of structuralfunctional analysis of medicines distribution produced in the Ural FD, pharmaceutical enterprises distribution by the medicines material flow concentration degree at a distributor of a certain level was obtained (Fig. 1).

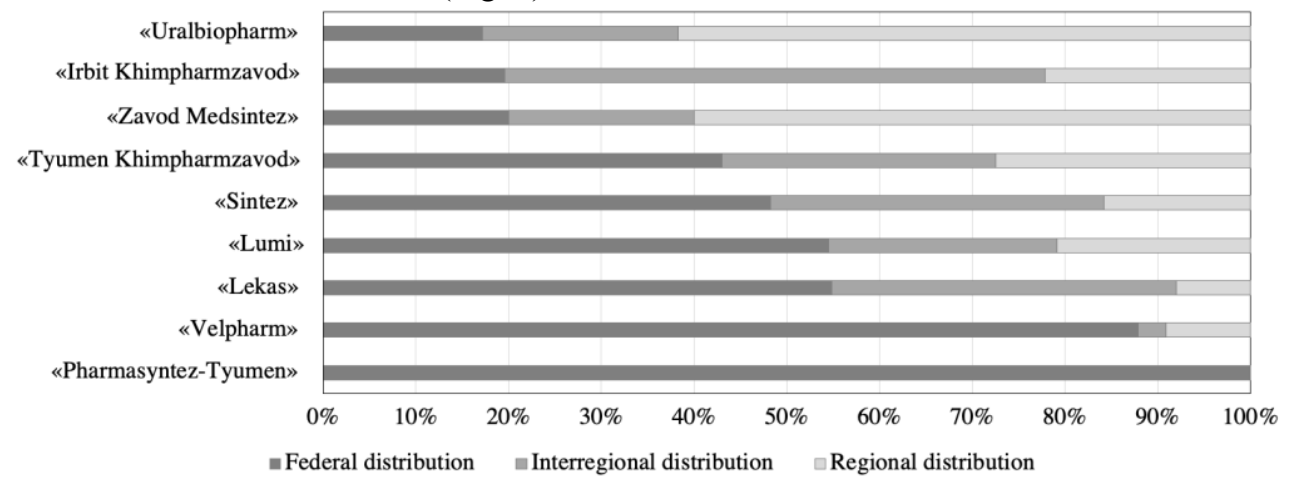

Fig. 1. Distribution of pharmaceutical enterprises of the Ural FD by the medicines' material flow concentration degree at a distributor of a certain level.

It should be noted that the supply structure of medicines produced in the Ural FD is heterogeneous and depends on a particular manufacturer. A number of enterprises use a consolidated intensive distribution channel with a high share of federal distribution ("Pharmasintez-Tyumen" LLC, "Lekas" CJSC, "Velpharm" LLC), the rest are characterized by logistics channels diversification with varying share of national suppliers from $17.2 \%$ to 
$54.9 \%$. The wide variation range is due to the specificity of the distributable product, marketing transactions, and economic characteristics of freight turnover units. The aspect of different diversification degrees seems particularly interesting from the perspective of logistical risks in the medicines distribution system and can serve as one of the risk metrics.

For the purpose of assessing the economic metrics impact on the logistics of medicines produced in the Ural FD, price analysis was conducted for all $474 \mathrm{TN}$ of medicines, for which the average annual wholesale price according to the "Svodny zakaz", "Eprika" platforms was determined. The joint distribution of medicines from the aggregated assortment portfolio of Ural pharmaceutical plants was built according to two parameters: TN price and the share of a certain distribution level. The distribution results are shown in Figure 2.

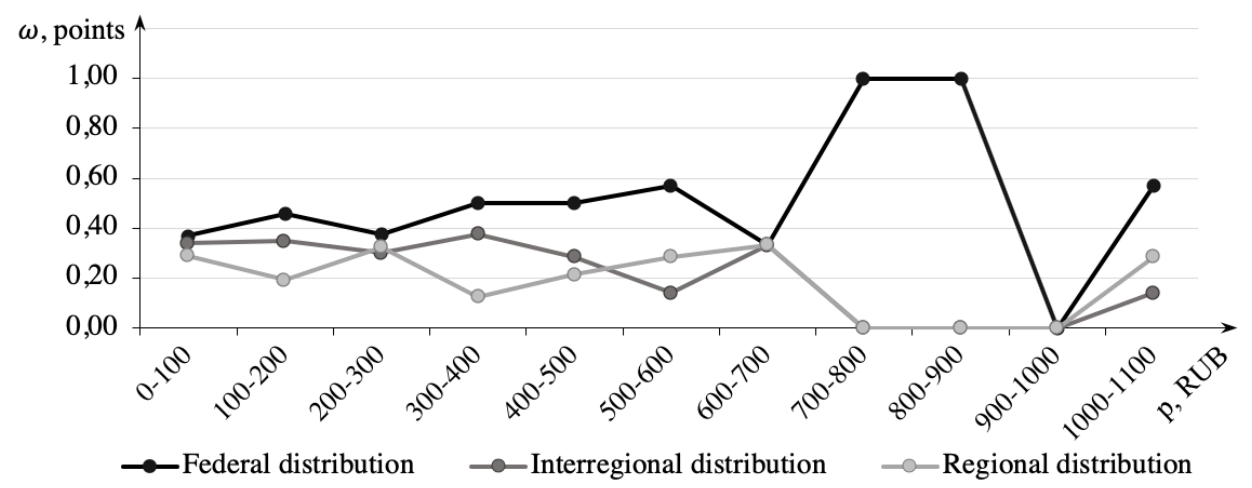

Fig. 2. Concentration of material flow in the medicines supply chain produced in the Ural FD depending on the price segment.

When analyzing the results of the received distribution, it is worth noting the priority of the federal distribution channel for all price segments. The increase in the share of federal distribution with the increase in the price of packaging of the medication is also of interest. In the price segment from 700 to 1100 rubles the share of federal suppliers varies from 60 to $100 \%$. Distribution concentration through federal suppliers increases the intensity of material flow distribution and guarantees representation in more subjects of the Russian Federation, which is a positive competitiveness factor for the product and manufacturer. However, the lack of diversification in the high-priced segment is a negative factor in the pharmaceutical care availability due to the limited availability of local extensive distribution of medicines produced in the Ural FD. In this case, there is a dual medicines distribution appearing in the local market with the federal suppliers' predominance, which prevents the reduction of market price in wholesale and retail segment of the Ural FD's pharmaceutical market.

Due to significant fluctuations in the natural distribution index within price ranges and to define the economic regularities of the medicines distribution, a dependency of the upper limit of the price range and the Herfindahl-Hirschman Index (HHI) calculated according to the distribution channels diversification parameters in this price segment was built. Further, the function was differentiated in the price range from 0 to $1100,99 \%$ of the current medications distribution in this price range produced in the Urals is concentrated. The economic meaning of the derivative function of the Herfindahl-Hirschman Index (by the diversification degree) from the price is the detection of institutional demand growth in the pharmaceutical market large wholesale segment for products of Ural pharmaceutical plants (Fig. 3a). The resulting pattern reflects the price elasticity of the concentration of wholesale turnover at national pharmaceutical distributors. It is worth noting the specific profile of the turnover concentration elasticity curve, which allows to highlight price segments with low, neutral and high logistics centralization price elasticity. 
According to the results of the stock remainders panel detection for 2019, it was determined that $95 \%$ of the medicines distribution are in the zone of negative price elasticity of trade turnover concentration, which shows that the base part of the range in the distribution is in the indifference segment to the "background" demand price for low-price medications. This segment is characterized by competition of manufacturers due to the low potential yield of the product in distribution channels. In addition, the assortment specificity of this sector is in the distribution of reproduced medications in low price segment. In the $\mathrm{HHI}<0$ segment, the prevailing risk factors are commercial ones defined by low trade mark-up value to compensate potential logistics and marketing expenses. In this segment, $12.5 \%$ of medicines can be used for pharmacotherapy of chronic heart diseases in geriatric practice, which brings additional social importance to logistics systems optimization. The segment $\left(\mathrm{HHI}^{\top}>0\right)$ is characterized by the active interest of federal distribution in expensive medicines from the aggregated portfolio of Ural pharmaceutical plants. The main risk factors in this sector are logistical, which lie in the lack of distribution channels diversification in the federal market for high-price medications. It is also worth to note the small number of expensive medicines produced in the Ural FD in the warehouses of federal suppliers. Thus, the definition of logistic risk parameters is particularly important for the segment of expensive and innovative medicines produced in the Urals. Table 1 provides the reasoning for the proposed logistical risk metrics.
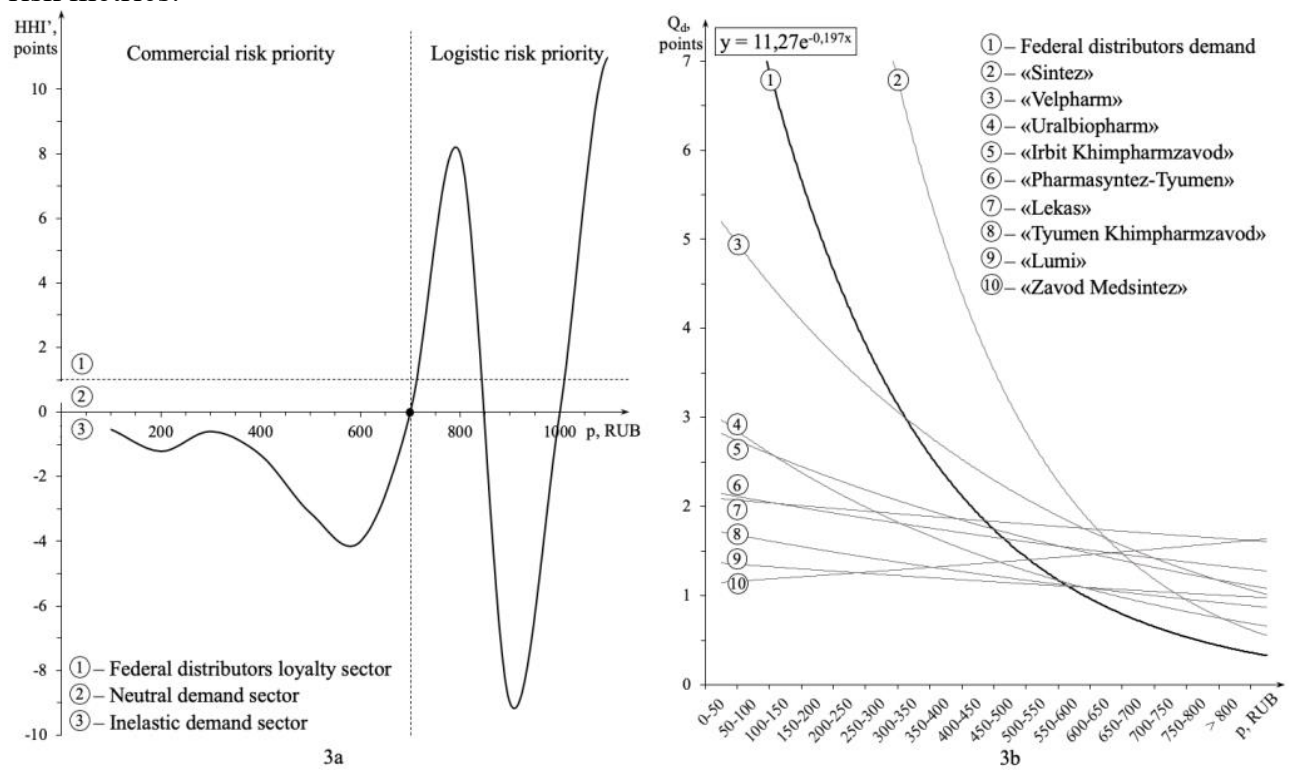

Fig. 3a. Price elasticity of wholesale turnover concentration at federal pharmaceutical distributors.

Fig. 3b. Model of demand in wholesale federal segment of pharmaceutical market and supply of pharmaceutical plants of the Ural FD

Due to the revealed pattern of federal suppliers realized demand concentration in the lowprice segment and high demand potential in the higher price segment, the analysis was conducted to check the conformity of the Ural FD's specific pharmaceutical plants supply to the price structure of supply in the wholesale federal segment of the pharmaceutical market. For this purpose, the empirical function of national suppliers' demand was determined and the supply functions of individual medicines manufacturers in the Ural FD were modeled. Supply and demand models were constructed in the value and price segment coordinates of the demand/supply. (Fig. 3b) The proposed model of supply-demand imbalance in the federal 
distribution segment for pharmaceutical plants of Ural FD was taken as the basis of commercial distributive logistics risk metrics determination. (Tab. 1).

Table 1. Distribution logistics risk multiplicators in the supply of medcations produced in the Ural FD

\begin{tabular}{|c|c|c|}
\hline $\begin{array}{c}\text { Distribution } \\
\text { logistics risk } \\
\text { multiplicators }\end{array}$ & $\begin{array}{l}\text { Basis of risk metrics } \\
\text { formation }\end{array}$ & Risk metrics \\
\hline $\begin{array}{l}\text { Marketing Risk } \\
\text { Multiplier } \\
\text { (MRM) }\end{array}$ & $\begin{array}{l}\text { The supply and demand } \\
\text { model in the federal } \\
\text { wholesale segment of the } \\
\text { pharmaceutical market }\end{array}$ & $\begin{array}{l}\text { Deviation of supply price characteristics of } \\
\text { certain pharmaceutical plants of Ural FD from } \\
\text { similar characteristics of federal suppliers } \\
\text { demand }\end{array}$ \\
\hline $\begin{array}{l}\text { Logistic risk } \\
\text { multiplier } \\
\text { (LRM) }\end{array}$ & 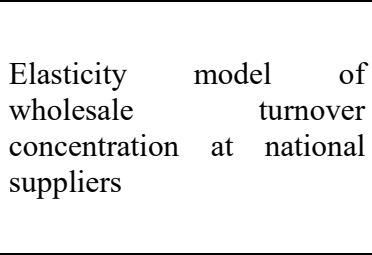 & $\begin{array}{l}\text { Sales and storage risks determined by turnover } \\
\text { of finished products stock remainders; } \\
\text { Organizational and pharmaceutical mobility } \\
\text { metric of the medication assortment determined } \\
\text { by assortment specialization indicator by ATC } \\
\text { groups, renewal degree and trade turnover } \\
\text { consolidation risk of small number of suppliers }\end{array}$ \\
\hline
\end{tabular}

Based on the results of the revealed heterogeneity of risk factors, an approach to modeling logistics risks based on two multiplicators is proposed: mercantile risk multiplier (MRM), logistics risk multiplier (LRM). Additive risk parameter (ARP) was proposed for a comprehensive assessment of distributive logistics risks of medicines produced in the Ural FD:

$$
A R P=M R M+L R M=\delta \_\left(Q_{s} / Q_{d}\right)+\alpha * F=\delta \_\left(Q_{s} / Q_{d}\right)+\alpha * K_{m o d} * K_{s p} * \Delta H H I
$$

$A R P$ - additive risk parameter;

$M R M$ - mercantile risk multiplicator, cond.units;

$L R M$ - logistics risk multiplicator, cond.units;

$\delta \_Q_{s} / Q_{d}$ - deviation of the plant supply value from the value of wholesale demand in each price range, unit;

$Q_{s}$ - supply value, pc;

$Q_{d}$ - the demand value, pc;

$\alpha$ - turnover of finished products' stock remainders, days;

$F$ - organizational and pharmaceutical metric of range mobility, cond.units;

$K_{\text {mod }}$ - the renewal factor of the plant's assortment portfolio, units;

$K_{s p}$ - coefficient of the plant's assortment portfolio specialization, units;

$\triangle H H I$ - Herfindahl-Hirschman Index, units.

Based on the results of the methodical approach approbation, risk mapping was carried out; figure 4 shows the distribution of pharmaceutical plants of the Ural FD according to additive risk parameter (ARP) indicator. Analyzing the distribution results, it is worth noting that the group of enterprises with high distribution logistics risks includes manufacturers of medicines with wide and updated assortment portfolios focused on federal suppliers ("Sintez" JSC, "Zavod Medsintez" LLC) in the average price range. The main group of businesses is located within the moderate risk range. Interpreting the model approbation results, it is possible to define methods of distribution risk reduction for medicines produced in the Ural FD: active promotion of medicines with a manufacturer's selling price excl.VAT of more than 700 rubles in the sector of federal suppliers' high elasticity demand, distribution channels diversification in the range of prices from 600 to 800 rubles. It is worth emphasizing that the medicines distribution logistics optimality with price over 600 rubles is important in terms of medicines availability for patients of older age groups outside the federal and regional beneficiary categories, which makes reducing logistical risk in this price segment a social priority. At the same time, one of the possible scenarios of distribution logistics 
diversification may be the attraction of state unitary enterprises licensed for wholesale pharmaceutical activity in the Ural FD.

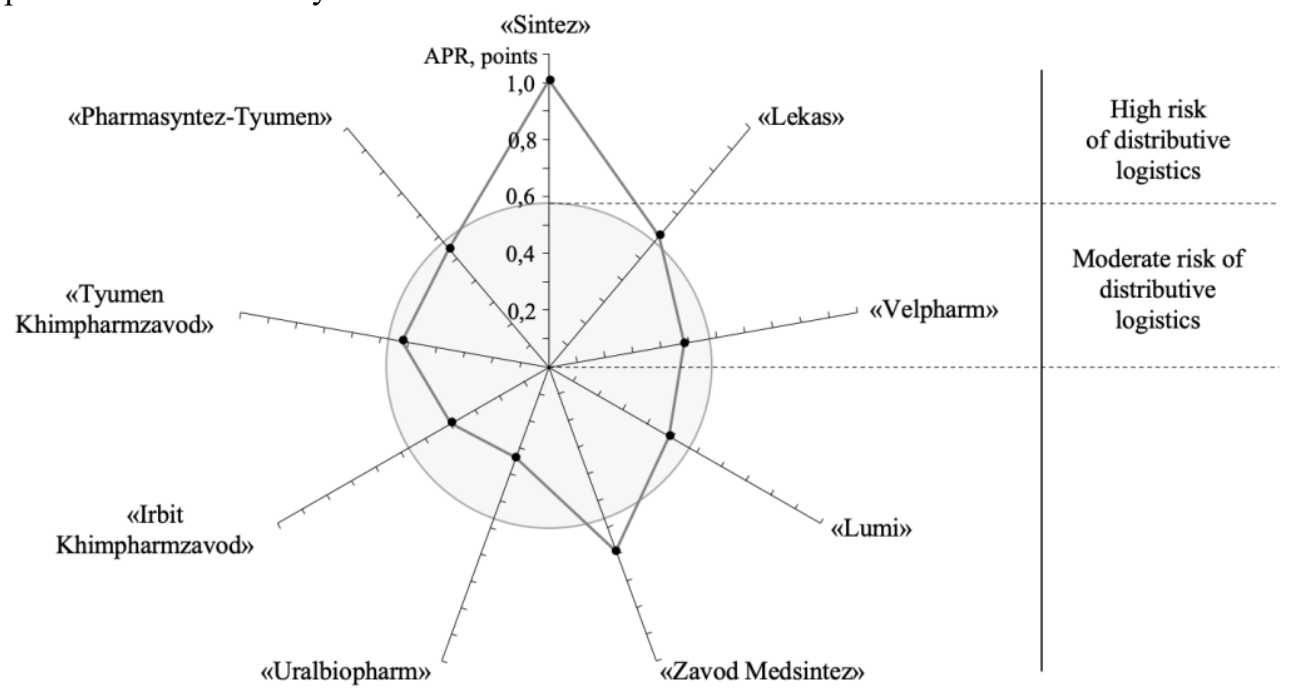

Fig. 4. Distribution logistics risk map for medications manufacturers localized in the Ural FD

\section{Conclusion}

1. Structural and functional analysis of medicines distribution system in the Ural FD was carried out. The heterogeneity of the medicines distribution system according to the coverage degree of the logistic intermediary was revealed, the concentration of trade turnover at federal distributors varied from from 17.2 to $100 \%$.

2. Methodical approach to pharmaceutical distribution logistics risk assessment in the Ural FD was proposed based on commercial and logistic risk multipliers for 9 system-forming enterprises of the pharmaceutical industry in the Ural FD. Organizational and pharmaceutical metrics of medications distribution logistics risks for Ural FD were substantiated. Mathematical modeling of demand in the segment of federal suppliers was carried out; mathematical modeling of the medicines supply in the context of individual Ural FD manufacturers was carried out; the supply and demand imbalance was determined by the metric of commercial risk.

3. Methodical approach to risk assessment of sales logistics of the Ural FD's industrial pharmaceutical sector has been tested; targeted recommendations to risk reduction of distribution logistics have been formed. The need for active medicines promotion in the price segment over 700 rubles per package was shown in the industry aspect. From the social importance of medicines supply system point of view, reducing the expensive medications logistics risks will lead to a decrease in the market price and demand of large wholesale intermediaries, which will form an additional availability for geriatric medicines use. The feasibility of attracting new logistics agents to the distribution system of medicines produced in the Ural FD and related to the price segment from 600 to 800 rubles was scientifically substantiated. Expansion of state unitary enterprises functionality in terms of sales logistics coordination of pharmaceutical plants of Ural FD was proposed to reduce logistic risks and increase competitiveness. 


\section{References}

1. A.L. Petrov, A.Y. Kantorovich, G.N. Andrianova, URMJ, 9, 130 (2019)

2. W. Sghaier, E. Hergon, A. Desroches, Transfus Clin Biol., 22, 158 (2015)

3. N.A. Gviliya, A.V. Parfyonov, T.G. Shulzhenko, Manager, 10, 40 (2019)

4. E.D. Mireli, Economy: yesterday, today, tomorrow, 5, 59 (2013)

5. O.V. Posylkina, Y. E. Novitskaya, A.G. Khromykh, Scientific Bulletin of Belgorod State University, 29, 202 (2015)

6. N.S. Klunko, 17, $3573(2016)$

7. E.V. Shalenkova, S.V. Kononova, E.V. Alakaeva, S.V. Petrova, Remedium, 10, 55 (2017)

8. I.B. Nikulina, G.N. Andrianova, Pharmacy, 4, 25 (2006)

9. I.K. Petrukhina, T.K. Ryazanova, R.I. Yagudina, E.P. Gladunova, Adv. Gerontol., 31, 789 (2018) 